\title{
FDA plans to improve and accelerate product reviews
}

Officials of the US Food and Drug Administration (FDA; Rockville, MD, USA) on March 16 launched an effort to accelerate products into and through the drug regulatory system. Although biotechnology industry representatives are praising the agency's 'critical path' initiative, questions are being raised about precisely what the agency is planning to do, and how soon and how well this new wish list can be implemented in the wake of Commissioner Mark McClellan's departure and amid the current political and budgetary turmoil.

"Today, as never before, we face a tremendous potential for new medicines to prevent and cure diseases, but fewer new products are actually reaching the FDA," said former commissioner McClellan when the agency released its report (see Fig. 1). The chief reason behind this disappointing trend, according to the agency report "Innovation or Stagnation?-Challenge and Opportunity on the Critical Path to New Medical Products," is that new science is not being "adequately harnessed to guide the technology development process in the same way that it is accelerating the discovery process."

Thus, agency officials are promising to work with scientists in industry, at other federal agencies such as the National Institutes of Health (NIH; Bethesda, MD) and at universities "to make the critical path [to product approval and marketing] much faster, predictable, and less costly." The next steps in this initiative include a series of workshops and meetings-for example, as Nature Biotechnology went to press, officials planned to devote the April Science Board meeting with stakeholders to this topic.

According to the FDA, this effort includes "a new focus on modernizing the tools that applied biomedical researchers and product developers use to assess the safety and effectiveness of potential new products, and the manufacturing tools necessary for highquality mass production of cutting-edge therapies." Carl Feldbaum, president of Biotechnology Industry Organization (BIO; Washington, DC), hopes this new "product development toolkit" will "eliminate inefficiencies and...lower costs." $\mathrm{He}$ stresses the importance of this because "the enormous costs and difficulties associated with moving research from the lab bench to the patient cannot be overstated."

Both McClellan and current acting commissioner Lester Crawford say that imple-

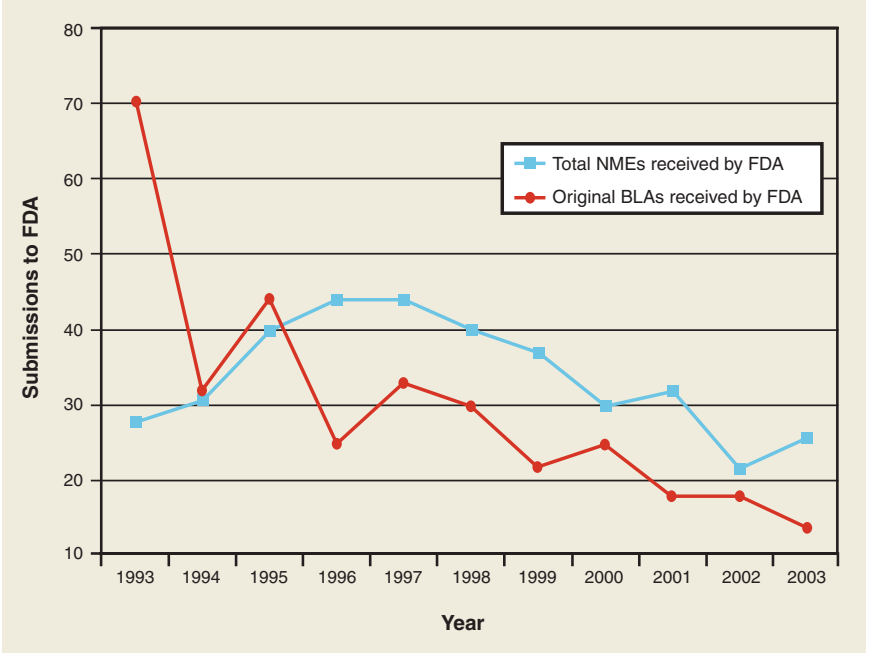

Figure 1 10-year trends in major drug and biological product submissions to the US FDA. NME, new molecular entity; BLA, biologics license application. Regulatory agencies worldwide have observed similar trends. Source: US FDA.

menting the critical path initiative will depend in part on the FDA developing and funding new research programs, while also expanding agency capacity for its more customary regulatory activities. The need for this augmented capacity anticipates a surge in candidate products - mainly from industry, but with some of them expected because of a buildup resulting from the $\mathrm{NIH}$ annual budget's doubling during the past five years to about $\$ 28$ billion.

\section{It is unlikely that the FDA will have new resources for new research programs}

NIH Director Elias Zerhouni's 2003 Roadmap Initiative emphasizes 'translational' research among several goal-oriented pledges to increase the efficiency of efforts to bring therapeutic products into clinical use (Nat. Biotechnol. 21, 1253-1254, 2003). The FDA report applauds such advances and concludes that the agency should undertake a third type of research beyond the familiar "basic and translational." This other kind of research entails targeting "the process of creating safe and effective products from new scientific discoveries."

Exactly what FDA officials have in mind remains uncertain, according to Sara Radcliffe, BIO's director of science and regulatory affairs. Agency scientists in some cases might need "to get in the lab and kick start the process and set the framework- for example, as to appropriate animal studies needed to evaluate vaccines because companies need to know what tests will be required," she says. But beyond such efforts, she adds, scientists working in the private sector should be choosing animal models and studying how best to use them, while the agency continues to focus on its principal mission of being a regulator. "I don't think it appropriate for FDA to aim at becoming a research organization."

Top NIH officials appear to be on board with the new FDA plan, but their approval is no surprise, because both agencies operate within the Department of Health and Human Services (Washington, DC, USA) under secretary Tommy Thompson, who is insistent on such agreement within the department. However, in view of current constraints on the federal budget, it is unlikely that the FDA will have new resources for new research programs, meaning this initiative will depend on redirected funds.

Meanwhile, agency officials have "extended an invitation to stakeholders to help them make this more concrete," says Radcliffe, noting that ample "leadership is in place" through acting commissioner Crawford, Cross Center Initiatives Taskforce director Janet Woodcock and other centers' directors to pursue this initiative. "BIO is taking this very seriously," she adds, noting that BIO will be consulting with member companies to assemble specific examples of what might be done to improve current practices. "Industry and FDA have to come closer together," she says. Jeffrey L Fox, Washington 